\title{
Discretionary intake among Australian adults: prevalence of intake, top food groups, time of consumption and its association with sociodemographic, lifestyle and adiposity measures
}

\author{
Flavia Fayet-Moore ${ }^{1, *}$, Andrew McConnell ${ }^{1}$, Tim Cassettari $^{1}$, Kate Tuck ${ }^{1}$, Peter Petocz ${ }^{2}$ \\ and Jean $\mathrm{Kim}^{3}$ \\ ${ }^{1}$ Nutrition Research Australia, Level 13, 167 Macquarie Street, Sydney, NSW 2000, Australia: ${ }^{2}$ Department of \\ Statistics, Macquarie University, Sydney, NSW, Australia: ${ }^{3}$ Nestlé Australia, Rhodes, NSW, Australia
}

Submitted 19 February 2018: Final revision received 7 0ctober 2018: Accepted 29 October 2018: First published online 25 January 2019

\begin{abstract}
Objective: To profile discretionary food and beverage (DF) consumption among Australian adults.

Design: Cross-sectional analysis. Dietary and sociodemographic data were used to profile DF intake. Prevalence of DF consumption, DF servings ( 1 serving $=600 \mathrm{~kJ}$ ), nutrient contribution from DF and top DF food groups by self-reported eating occasions were determined. DF consumers $(>0 \mathrm{~g})$ were classified according to quartile of DF intake and general linear models adjusted for age and sex were used to determine associations.

Setting: 2011-12 National Nutrition and Physical Activity Survey (NNPAS).

Participants: Adults aged $\geq 19$ years ( $n$ 9341) who participated in the NNPAS 2011-12.

Results: Most adults consumed DF (98\%) and over $60 \%$ exceeded 3 DF servings/d, with a mean of $5 \cdot 0$ (se 0.0) DF servings/d. Cakes, muffins, scones, cake-type desserts contributed the most DF energy ( $8.4 \%$ ) of all food groups, followed by wines $(8 \cdot 1 \%)$, pastries $(8 \cdot 0 \%)$ and beers $(6 \cdot 1 \%)$, with all these food groups consumed in large portions (2.3-3.0 DF servings). Lunch and dinner together contributed $45 \%$ of total DF energy intake. High DF consumers had an average of 10 DF servings, and this group contained more younger adults, males, low socio-economic status, lower usual fruit intake and higher mean waist circumference, but not higher BMI.

Conclusions: A focus on DF consumed in large portions at lunch and dinner may help improve interventions aimed at reducing DF intake and addressing negative adiposity-related measures found in high DF consumers.
\end{abstract}

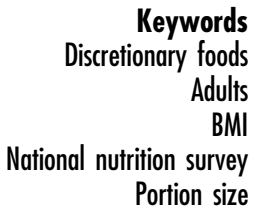

Portion size
Dietary guidelines worldwide recommend nutritious and health-promoting diets. In Australia, the Australian Dietary Guidelines encourage eating from the five core food groups: (i) fruit; (ii) vegetables and legumes/beans; (iii) lean meats and poultry, fish, eggs, tofu, nuts and seeds and legumes/beans; (iv) grain (cereal) foods; and (v) milk, yoghurt, cheese and/or alternatives ${ }^{(1)}$. Non-core foods and beverages are called 'discretionary foods and beverages' (DF). DF are defined as foods and drinks not necessary to provide the nutrients the body needs, and are high in saturated fat, added sugars, added salt or alcohol and low in fibre ${ }^{(2)}$. Other descriptive terms for DF include 'energydense, nutrient-poor foods', 'empty calories', 'extra foods' and 'high-energy-dense foods ${ }^{,(3-6)}$. The Australian Dietary Guidelines recommend DF to be consumed only occasionally and in small amounts, from 0 to 3 servings for males and 0 to 2.5 servings for females per day, with one serving containing $600 \mathrm{~kJ}^{(7)}$. The guidelines recommend that any additional energy requirements, such as for those who are taller or more physically active, should be met with servings from the core food groups or unsaturated spreads and oils in preference to discretionary choices ${ }^{(1)}$. Those who are overweight have no additional energy allowance and discretionary intake is discouraged, because the consumption of DF has been shown to increase the risk of weight gain and chronic disease ${ }^{(1,8-11)}$.

Sixty-three per cent of Australian adults are overweight or obese ${ }^{(12)}$ and chronic disease is the leading contributor to morbidity and mortality ${ }^{(13)}$. Therefore a large proportion of Australian adults have no energy allowance for DF, yet DF intake contributes $35 \%$ of their total energy intake $^{(14)}$. Large portion sizes may contribute to the 
overconsumption of DF. In an analysis of the 2011-12 National Nutrition and Physical Activity Survey (NNPAS) in Australia, the median portion size of cakes, savoury pastries, hamburgers and pizza exceeded the standard serving set by the dietary guidelines of $600 \mathrm{~kJ}$, by up to $400 \%{ }^{(15)}$. Given that the Australian Dietary Guidelines recommend no more than 3 DF servings daily for the majority of adults, many will be exceeding this limit from just a single portion of DF. At the same time, only $3.5 \%$ of adult males and $5 \cdot 2 \%$ of adult females met the recommended daily servings of vegetables and legumes/beans, and $29 \cdot 3 \%$ of adult males and $23.0 \%$ of adult females met the recommended daily servings of fruit ${ }^{(16)}$. With high discretionary intakes and low consumption of fruit and vegetables, DF could displace core foods, as reported in the USA ${ }^{(4)}$. Inadequate intake of core foods and excess consumption of discretionary foods may lead to the double burden of under- and overnutrition ${ }^{(17)}$. Hence, it is important to gain a deeper understanding of the role of DF in the diet of Australian adults to develop targeted strategies to assist in reducing its intake. While many studies focus on selected discretionary foods or beverages (e.g. sugar-sweetened beverages, salty snacks or foods high in saturated fats), a more thorough analysis of DF consumption patterns, including the highest energy contributors, in combination with consumer sociodemographic factors and adiposityrelated measures, is needed to assist both health professionals and government in developing public health strategies to address the excess intake of DF.

The aim of the present study was to examine, in a nationally representative sample of the Australian adult population, the prevalence of DF consumption, the top DF food groups in terms of contribution to discretionary energy, their contribution to total sugars, saturated fat and $\mathrm{Na}$ intakes, and the eating occasions (EO) where the most DF were consumed. We analysed these nutrients because they form the basis of the definition of $\mathrm{DF}^{(2)}$ and we wanted to see what influence DF had on the nutrients that should be limited. At the time of analysis, data on added sugars and salt were not available so we chose total sugars as a substitute for added sugars and $\mathrm{Na}$ as a substitute for salt. Further, we aimed to examine the sociodemographic and lifestyle characteristics of DF consumers and any associations of DF with adiposityrelated measures.

\section{Methods}

\section{Survey metbodology}

The Australian Bureau of Statistics conducted the Australian Health Survey (AHS) between 2011 and 2013 on a nationally representative sample of Australians aged 2 years or over. The 2011-12 NNPAS was part of the AHS and collected physical activity data and detailed dietary information from 12153 respondents. Trained interviewers used the automated multiple-pass method, which was developed by the Agricultural Research Service of the US Department of Agriculture ${ }^{(18)}$ and adapted to reflect the Australian food supply, to capture all foods and beverages consumed by respondents within the $24 \mathrm{~h}$ prior to the interview day. A second day of dietary recall was provided by telephone interview by approximately two-thirds ( $n$ 7735) of participants. Total energy and nutrient intakes were derived from Food Standards Australia New Zealand's customised nutrient composition database (AUSNUT) $^{(19)}$. To maximise the sample size, data from the first $24 \mathrm{~h}$ recall among 9341 adults aged 19 years or over were utilised. A sensitivity analysis was performed to investigate whether there were differences in DF consumed between day 1 and day 2 of recall. The top foods that contributed to discretionary energy were similar across the two days (see online supplementary material, Supplementary Table 1). Further survey details are available from the Australian Bureau of Statistics' website in the Australian Health Survey: Users' Guide, 2011-13(20).

Participants were classified by age group (19-30, 31-50, $51-70, \geq 71$ years), sex, socio-economic status (SES), physical activity level, adiposity-related measures, usual fruit and vegetable servings, and smoking status. The Socio-Economic Indexes for Areas (SEIFA) ${ }^{(21)}$ was used to define SES. SEIFA is a product developed by the Australian Bureau of Statistics that ranks areas in Australia into quintiles according to relative socio-economic advantage or disadvantage in terms of people's access to material and social resources and their ability to participate in society. The lowest SES quintile was defined as the first quintile and the highest as the fifth quintile.

Physical activity was self-reported as the amount of physical activity each respondent undertook in the week prior to the survey. The interviewers collecting the information relied on participants' recall, as no recording devices or other instruments were used to measure physical activity. The total number of minutes of physical activity was recorded, with one session equivalent to 30 min of moderate-intensity physical activity. The amount of time spent sitting or lying down for work, transport and leisure during the week prior to the survey was also selfreported by respondents. Respondents were classified based on the duration and number of sessions of physical activity into three categories: inactive, insufficiently active or sufficiently active for health ${ }^{(20)}$.

Interviewers measured the height, weight and waist circumference of consenting participants. A stadiometer was used to measure height, digital scales to measure weight, and a metal tape measure across the top of the belly button to measure waist circumference. Measured height and weight were used to calculate BMI $\left(\mathrm{kg} / \mathrm{m}^{2}\right)$ and respondents were categorised based on the WHO definitions $^{(22)}$. Respondents were categorised according to their measured waist circumference and classified based on their waist size into the WHO categories for level of risk of 
metabolic complications: not at risk $(<80 \mathrm{~cm}$ for females, $<94 \mathrm{~cm}$ for males), increased risk ( $\geq 80$ and $<88 \mathrm{~cm}$ for females, $\geq 94$ and $<102 \mathrm{~cm}$ for males) or substantially increased risk ( $\geq 88 \mathrm{~cm}$ for females, $\geq 102 \mathrm{~cm}$ for males $)^{(23)}$.

Respondents were asked to specify the usual number of fruit and vegetable servings consumed per day from the following options: 'don't eat fruit/vegetables', 'less than 1 serve, '1 serve, '2 serves', '3 serves', '4 serves', '5 serves' or ' 6 or more serves'. To determine mean number of servings we defined 'don't eat fruit/vegetables' as 0 , 'less than 1 serve' as 0.5 and ' 6 or more serves' as 6 .

\section{Under-reporters}

BMR is the amount of energy needed for an individual's minimum set of body functions necessary for life over a defined time period. BMR is given in kilojoules per $24 \mathrm{~h}$ and calculated using age, sex and weight (kilograms) as variables with no adjustment for activity levels. The ratio of energy intake (EI) to BMR (EI:BMR) was used to calculate under-reporters as participants with implausibly low intakes. Participants were classified as under-reporters or not under-reporters based on the Goldberg ${ }^{(24)}$ cut-off limit of 0.9 for EI:BMR, which is the lower $95 \%$ confidence limit for a single day of data for a single individual, allowing for day-to-day variation in energy intakes and errors in calculation of EI:BMR.

\section{Dietary intake}

DF are defined by the Australian Dietary Guidelines as foods and beverages not necessary to provide the nutrients the body needs, and are high in saturated fats, added sugars, added salt or alcohol and low in fibre ${ }^{(2)}$. The Australian Bureau of Statistics categorised food groups in the survey as discretionary or non-discretionary based on these definitions and the supporting documents that underpin the Australian Dietary Guidelines. There are discretionary food and beverage items, such as diet soft drinks, that do not contain any energy. While these foods and beverages did not contribute to results relating to discretionary energy intake, they were included in all other relevant results such as prevalence of discretionary consumers. Foods were classified primarily at the minor food group level (5-digit); where it was not possible to determine if a food was discretionary at this level, the unique food code level (8-digit) was used along with the nutrient profiling cut-offs used in the Australian Dietary Guidelines modelling document ${ }^{(25)}$. Discretionary food and beverage groups in the present study are reported at the sub-major food group level (3-digit). There was a total of 132 sub-major food groups in the AUSNUT database, and sixty of these food groups contained a discretionary food or beverage. Henceforth, discretionary food groups (or 'DF food group') refers to the discretionary foods and beverages in the sub-major food group.
As part of the survey, respondents were asked to identify the name of their reported eating occasion (REO) as well as the time they began consuming each food or beverage. There were eleven REO available for selection: breakfast, morning tea, brunch, lunch, afternoon tea, dinner, supper, snack, beverage/drink, extended consumption or other ${ }^{(20)}$. As the choice of REO was subjective, respondents could report similar eating patterns in different ways. For example, a glass of wine with the evening meal could be reported by one respondent as 'dinner' and by another respondent as 'beverage/drink'. We defined an EO as the consumption of one or more foods or beverages at the same time with the same REO.

\section{Statistical analysis}

The mean DF intake in servings ( 1 serving $=600 \mathrm{~kJ}$ ), the proportion of total energy intake from DF and total daily energy intake were calculated. To investigate frequency and timing of DF intake, we calculated the proportion of the EO that contained DF and the percentage contribution of each REO to total DF energy. For food groups, we determined the prevalence of consumers of each DF food group among DF consumers and the mean intake, in servings and in grams, among consumers of each DF food group. We calculated the percentage contribution of each food group to total DF energy, and to total sugars, saturated fat and $\mathrm{Na}$ intakes among $\mathrm{DF}$ consumers. Among the top four REO that contributed the most to daily DF energy, we determined the top five sub-major food groups, the percentage of total DF energy that it contributed at the REO and the mean kilojoules among consumers of the food group. Quartiles of the percentage energy contribution from DF were used to classify adults as low consumers (quartile 1) and high consumers (quartile 4).

The statistical software package IBM SPSS Statistics version 23.0 was used for all analyses. Due to the large sample size and the number of tests, we felt that to classify $P$ values $<0.05$ as significant would lead to many type 1 errors; so we treated $P$ values $<0.001$ as significant. Data were weighted to the Australian population using weights provided by the Australian Bureau of Statistics. Descriptive summaries were calculated for all variables of interest. ANOVA tables were produced to calculate se of the mean. Associations between quartiles of DF energy contribution and demographic and adiposity-related measures and lifestyle characteristics were examined using Pearson's $\chi^{2}$ tests. General linear models were created using univariate ANOVA to estimate the effect of age group, sex, their interaction and quartiles of DF energy contribution on dietary metrics, adiposity-related measures and lifestyle characteristics. Post boc pairwise comparisons using the Bonferroni correction were performed to show pairwise significance between quartiles of DF energy contribution. 


\section{Results}

Almost all adults consumed DF (97.5\%; Table 1). Over $60 \%$ of adults had more than the maximum recommended $3 \mathrm{DF}$ servings/d, with a per capita mean of $5 \cdot 0$ (SE 0.0). More than $50 \%$ of males and females of all age groups, apart from females 51 years of age or over, consumed more than $3 \mathrm{DF}$ servings/d. Young males and females aged 19-30 years had the highest daily mean DF servings (6.7 (SE 0.2) servings/d for males, 4.6 (sE 0.1) servings/d for females). Consumption of DF decreased with age for both males and females, with the $\geq 71$ years age group having the lowest mean servings for each sex (4.9 (se 0.2) for males, 3.5 (se 0.1) for females). Males had a greater DF energy intake than females for all age groups, both in total and as a proportion of total energy intake. The proportion of total energy from DF was greater than $30 \%$ for all age and sex groups except females aged 51-70 years (28.6 (se 0.5)\%), and this age group also had the highest prevalence of non-consumers of DF (3.8\%). For each age group, males had a lower number of total daily EO than females, but more of their EO contained DF, and therefore the proportion of EO that contained DF was higher among males than females. About half of all EO contained DF: between 55 and $58 \%$ for males and between 46 and $51 \%$ for females.

\section{Which food groups contributed the most to discretionary intake?}

Among DF consumers, the top four DF food groups ranked by contribution to daily DF energy intake were: cakes, muffins, scones, cake-type desserts (8.4\%); wines
( $8.1 \%)$; pastries ( $8.0 \%)$; and beers (6.1\%; Table 2$)$. These top four food groups had large portion sizes, ranging from 2.3 to 3.0 DF servings; however, none of these food groups made the top four when ranked by popularity (prevalence of consumers). The top contributor to DF energy intake - cakes, muffins, scones, cake-type desserts - was consumed by only $16 \%$ of DF consumers, but had a large mean portion size of 3 DF servings, or $123 \mathrm{~g}$, per consumer. The top four food groups ranked by popularity (sugar, honey and syrups; soft drinks and flavoured mineral waters; processed meat; sweet biscuits) had between 22.4 and $48.5 \%$ of consumers, and small mean portion sizes ranging between 0.5 and 1.1 mean DF servings per consumer. Sugar, honey and syrups was the most popular food group with $48.5 \%$ of DF consumers, but the mean DF servings per consumer was 0.5 , and it was ranked only seventh by contribution to total DF energy intake.

Three of the top five DF food groups by contribution to DF energy intake were beverages: two alcoholic beverages (wines; beers) and one non-alcoholic beverage (soft drinks and flavoured mineral waters). Of the top twenty DF food groups, processed meat contributed the most to $\mathrm{Na}$, pastries the most to saturated fat, and soft drinks and flavoured mineral waters the most to total sugars.

\section{Which food groups, during which reported eating occasions, contributed the most to discretionary intake?}

The top four REO by contribution to total discretionary energy were dinner, lunch, snack and beverage/drink,

Table 1 Baseline characteristics of the sample of Australian adults aged $\geq 19$ years $(n$ 9341) from the 2011-12 National Nutrition and Physical Activity Survey

\begin{tabular}{|c|c|c|c|c|c|c|c|c|c|c|c|c|c|c|c|c|c|c|}
\hline & \multicolumn{4}{|c|}{$19-30$ years } & \multicolumn{4}{|c|}{$31-50$ years } & \multicolumn{4}{|c|}{$51-70$ years } & \multicolumn{4}{|c|}{$\geq 71$ years } & & \\
\hline & \multicolumn{2}{|c|}{ Males } & \multicolumn{2}{|c|}{ Females } & \multicolumn{2}{|c|}{ Males } & \multicolumn{2}{|c|}{ Females } & \multicolumn{2}{|c|}{ Males } & \multicolumn{2}{|c|}{ Females } & \multicolumn{2}{|c|}{ Males } & \multicolumn{2}{|c|}{ Females } & \multicolumn{2}{|c|}{$\begin{array}{l}\text { All adults } \\
\geq 19 \text { years }\end{array}$} \\
\hline & $n$ & $\%$ & $n$ & $\%$ & $n$ & $\%$ & $n$ & $\%$ & $n$ & $\%$ & $n$ & $\%$ & $n$ & $\%$ & $n$ & $\%$ & $n$ & $\%$ \\
\hline \multicolumn{19}{|l|}{$\begin{array}{l}\text { Prevalence of } \\
\text { consumers by DF } \\
\text { servings }\end{array}$} \\
\hline $\begin{array}{l}\text { Non-consumers } \\
>0-1 \text { servings* } \\
>1-3 \text { servings } \\
>3-5 \text { servings } \\
>5 \text { servings }\end{array}$ & $\begin{array}{r}35 \\
79 \\
214 \\
208 \\
580\end{array}$ & $\begin{array}{r}3 \cdot 1 \\
7 \cdot 1 \\
19 \cdot 2 \\
18 \cdot 6 \\
52 \cdot 0\end{array}$ & $\begin{array}{r}21 \\
154 \\
291 \\
204 \\
401\end{array}$ & $\begin{array}{r}2 \cdot 0 \\
14 \cdot 4 \\
27 \cdot 2 \\
19 \cdot 0 \\
37 \cdot 4\end{array}$ & $\begin{array}{r}37 \\
149 \\
338 \\
328 \\
905\end{array}$ & $\begin{array}{r}2 \cdot 1 \\
8 \cdot 5 \\
19 \cdot 2 \\
18 \cdot 7 \\
51 \cdot 5\end{array}$ & $\begin{array}{r}44 \\
257 \\
508 \\
410 \\
560\end{array}$ & $\begin{array}{r}2.5 \\
14 \cdot 4 \\
28 \cdot 6 \\
23 \cdot 0 \\
31 \cdot 5\end{array}$ & $\begin{array}{r}30 \\
115 \\
289 \\
265 \\
636\end{array}$ & $\begin{array}{r}2 \cdot 2 \\
8 \cdot 6 \\
21 \cdot 6 \\
19 \cdot 9 \\
47 \cdot 6\end{array}$ & $\begin{array}{r}52 \\
226 \\
433 \\
278 \\
389\end{array}$ & $\begin{array}{r}3 \cdot 8 \\
16 \cdot 4 \\
31 \cdot 4 \\
20 \cdot 2 \\
28 \cdot 2\end{array}$ & $\begin{array}{r}6 \\
42 \\
124 \\
116 \\
175\end{array}$ & $\begin{array}{r}1 \cdot 3 \\
9 \cdot 1 \\
26 \cdot 8 \\
25 \cdot 1 \\
37 \cdot 8\end{array}$ & $\begin{array}{r}13 \\
69 \\
212 \\
152 \\
115\end{array}$ & $\begin{array}{r}2 \cdot 3 \\
12 \cdot 3 \\
37 \cdot 8 \\
27 \cdot 1 \\
20 \cdot 5\end{array}$ & $\begin{array}{r}238 \\
1091 \\
2409 \\
1961 \\
3761\end{array}$ & $\begin{array}{r}2.5 \\
11.5 \\
25.5 \\
20.7 \\
39.8\end{array}$ \\
\hline & Mean & SE & Mean & SE & Mean & SE & Mean & $\mathrm{SE}$ & Mean & $\mathrm{SE}$ & Mean & SE & Mean & SE & Mean & $\mathrm{SE}$ & Mean & SE \\
\hline DF servings/d & $6 \cdot 7$ & 0.2 & 4.6 & 0.1 & $6 \cdot 3$ & 0.1 & $4 \cdot 1$ & 0.1 & 5.5 & 0.1 & 3.7 & 0.1 & 4.9 & 0.2 & 3.5 & 0.1 & $5 \cdot 0$ & 0.0 \\
\hline Energy intake (MJ) & $11 \cdot 0$ & 0.1 & 7.9 & $0 \cdot 1$ & $10 \cdot 2$ & 0.1 & 7.5 & $0 \cdot 1$ & $9 \cdot 3$ & 0.1 & $7 \cdot 3$ & 0.1 & $8 \cdot 2$ & 0.1 & $6 \cdot 6$ & 0.1 & 8.7 & 0.0 \\
\hline $\begin{array}{l}\text { Proportion of energy } \\
\text { from DF (\%) }\end{array}$ & $34 \cdot 8$ & 0.7 & $33 \cdot 1$ & 0.7 & $34 \cdot 6$ & 0.5 & $31 \cdot 1$ & 0.5 & 33.9 & 0.6 & $28 \cdot 6$ & 0.5 & 33.4 & 0.9 & $30 \cdot 1$ & 0.8 & 32.5 & 0.2 \\
\hline $\mathrm{EO} / \mathrm{d}$ & $6 \cdot 4$ & 0.1 & $6 \cdot 6$ & 0.1 & $7 \cdot 0$ & 0.1 & $7 \cdot 2$ & 0.1 & $6 \cdot 9$ & 0.1 & $7 \cdot 4$ & 0.1 & $6 \cdot 7$ & 0.1 & $7 \cdot 0$ & 0.1 & $6 \cdot 9$ & 0.0 \\
\hline EO with DF/d & 3.5 & 0.1 & $3 \cdot 3$ & 0.0 & 3.9 & 0.0 & 3.5 & 0.0 & 3.7 & 0.1 & $3 \cdot 3$ & 0.1 & 3.8 & 0.1 & 3.5 & 0.1 & $3 \cdot 6$ & 0.0 \\
\hline $\begin{array}{l}\text { Proportion of EO } \\
\text { with DF (\%) }\end{array}$ & $55 \cdot 0$ & 0.7 & $51 \cdot 2$ & 0.6 & $56 \cdot 4$ & 0.6 & $49 \cdot 9$ & 0.5 & $55 \cdot 4$ & 0.7 & $45 \cdot 5$ & 0.6 & $57 \cdot 6$ & 1.1 & $50 \cdot 9$ & 1.0 & $52 \cdot 4$ & 0.2 \\
\hline
\end{tabular}


Table 2 Proportion of consumers, energy and nutrient contributions, and serving size of the top twenty sub-major food groups that contained discretionary foods and beverages (DF), ranked by percentage energy contribution, among Australian adults aged $\geq 19$ years ( $n 9341$ ) from the 2011-12 National Nutrition and Physical Activity Survey

\begin{tabular}{|c|c|c|c|c|c|c|c|c|}
\hline Rank & $\begin{array}{l}\text { Sub-major food } \\
\text { group }\end{array}$ & $\begin{array}{l}\text { Proportion } \\
\text { of DF } \\
\text { consumers } \\
\quad(\%)\end{array}$ & $\begin{array}{l}\text { Contribution to } \\
\text { DF energy } \\
\text { among DF } \\
\text { consumers } \\
(\%)\end{array}$ & $\begin{array}{l}\text { DF servings } \\
\text { among } \\
\text { consumers of } \\
\text { the food group } \\
\text { (mean) }\end{array}$ & $\begin{array}{l}\text { DF grams } \\
\text { among } \\
\text { consumers of } \\
\text { the food group } \\
\text { (mean) }\end{array}$ & $\begin{array}{l}\text { Contribution to } \\
\text { total sugars } \\
\text { among DF } \\
\text { consumers } \\
(\%)\end{array}$ & $\begin{array}{c}\text { Contribution to } \\
\text { total saturated } \\
\text { fat among DF } \\
\text { consumers } \\
(\%)\end{array}$ & $\begin{array}{c}\text { Contribution } \\
\text { to total Na } \\
\text { among DF } \\
\text { consumers } \\
(\%)\end{array}$ \\
\hline 1. & $\begin{array}{l}\text { Cakes, muffins, } \\
\text { scones, cake-type } \\
\text { desserts }\end{array}$ & $15 \cdot 6$ & 8.4 & 3.0 & $122 \cdot 5$ & $5 \cdot 6$ & $4 \cdot 7$ & $2 \cdot 4$ \\
\hline 2. & Wines & $18 \cdot 0$ & $8 \cdot 1$ & $2 \cdot 3$ & 428.9 & 0.5 & 0.0 & 0.6 \\
\hline 3. & Pastries & 14.4 & 8.0 & $2 \cdot 8$ & $169 \cdot 4$ & $1 \cdot 1$ & 4.9 & 4.1 \\
\hline 4. & Beers & 13.7 & $6 \cdot 1$ & $2 \cdot 6$ & $1122 \cdot 1$ & 0.1 & 0.0 & 0.5 \\
\hline 5. & $\begin{array}{l}\text { Soft drinks and } \\
\text { flavoured mineral } \\
\text { waters }\end{array}$ & $27 \cdot 5$ & $5 \cdot 2$ & 0.9 & $545 \cdot 7$ & $9 \cdot 2$ & 0.0 & 0.8 \\
\hline 6. & Sweet biscuits & $22 \cdot 4$ & $5 \cdot 1$ & $1 \cdot 1$ & $32 \cdot 2$ & $2 \cdot 2$ & 3.1 & 0.9 \\
\hline 7. & $\begin{array}{l}\text { Sugar, honey and } \\
\text { syrups }\end{array}$ & $48 \cdot 5$ & 4.9 & 0.5 & $18 \cdot 1$ & 7.9 & 0.0 & 0.0 \\
\hline 8. & $\begin{array}{l}\text { Chocolate and } \\
\text { chocolate-based } \\
\text { confectionery }\end{array}$ & $16 \cdot 7$ & $4 \cdot 8$ & 1.5 & $42 \cdot 5$ & 3.6 & $4 \cdot 1$ & 0.3 \\
\hline 9. & $\begin{array}{l}\text { Frozen milk } \\
\text { products }\end{array}$ & $13 \cdot 3$ & 3.9 & 1.5 & $108 \cdot 9$ & $2 \cdot 8$ & 3.6 & 0.3 \\
\hline 10. & Potatoes & 11.7 & 3.9 & 1.7 & 98.7 & 0.0 & 1.2 & 0.8 \\
\hline 11. & Processed meat & $22 \cdot 6$ & 3.5 & 0.7 & $52 \cdot 3$ & 0.1 & $2 \cdot 0$ & $6 \cdot 4$ \\
\hline 12. & $\begin{array}{l}\text { Sausages, } \\
\text { frankfurts and } \\
\text { saveloys }\end{array}$ & $6 \cdot 2$ & $3 \cdot 3$ & $2 \cdot 8$ & $154 \cdot 4$ & 0.0 & $3 \cdot 1$ & $3 \cdot 1$ \\
\hline 13. & $\begin{array}{l}\text { Fish and seafood } \\
\text { products } \\
\text { (homemade and } \\
\text { takeaway) }\end{array}$ & $5 \cdot 0$ & 3.0 & 2.9 & $187 \cdot 8$ & 0.1 & 0.8 & $1 \cdot 3$ \\
\hline 14. & $\begin{array}{l}\text { Mixed dishes where } \\
\text { cereal is the major } \\
\text { ingredient }\end{array}$ & $3 \cdot 6$ & $2 \cdot 7$ & 4.0 & $225 \cdot 0$ & 0.2 & $1 \cdot 7$ & $1 \cdot 7$ \\
\hline 15. & Salad dressings & $14 \cdot 2$ & $2 \cdot 3$ & 0.7 & 22.5 & 0.2 & 0.7 & 0.9 \\
\hline 16. & Butters & $16 \cdot 1$ & $2 \cdot 0$ & 0.6 & 11.8 & 0.0 & 3.7 & 0.5 \\
\hline 17. & $\begin{array}{l}\text { Fruit and vegetable } \\
\text { juices, and drinks }\end{array}$ & $7 \cdot 8$ & $2 \cdot 0$ & $1 \cdot 2$ & 386.5 & $3 \cdot 1$ & 0.0 & 0.1 \\
\hline 18. & Potato snacks & $6 \cdot 1$ & 1.7 & 1.6 & $44 \cdot 1$ & 0.1 & 0.7 & 0.8 \\
\hline 19. & Cordials & $6 \cdot 3$ & 1.6 & 1.3 & 602.5 & $2 \cdot 8$ & 0.0 & 0.1 \\
\hline 20. & $\begin{array}{l}\text { Other alcoholic } \\
\text { beverages }\end{array}$ & $3 \cdot 1$ & 1.6 & $2 \cdot 9$ & $624 \cdot 6$ & $1 \cdot 6$ & 0.2 & 0.1 \\
\hline
\end{tabular}

which in total contributed $75 \%$ of total DF energy (Table 3). Lunch and dinner together contributed almost half ( $45 \%$ ) of all DF energy, and snack and beverage/ drink almost a third (30\%). The top contributors at dinner, lunch, snack and beverage/drink were wines (15\%), pastries (17\%), chocolate and chocolate-based confectionery (21\%) and beers (25\%), respectively.

In addition to beers, the second-highest contributor to the REO beverage/drink was also an alcoholic beverage (wines contributed 20\%), and both these beverages were consumed in substantially higher portion sizes (at least three times more kilojoules per consumer) than the other food groups in this REO. The top four food groups that contributed to DF energy during snack were all significant sources of total sugars and saturated fat, whereas those at lunch and dinner were significant sources of $\mathrm{Na}$ and saturated fat. As well as being the top contributor to DF energy at lunch, pastries (croissants,
Danish pastries, pies, sausage rolls, quiches, spring rolls, etc.) contributed the second-most DF energy to dinner. Other food groups that were top-five DF contributors in two different REO were soft drinks and flavoured mineral waters (lunch and beverage/drink) and cakes, muffins, scones, cake-type desserts (lunch and snack).

\section{Characteristics of adults by proportion of energy from discretionary foods and beverages}

The DF contribution to total daily energy in quartile 1 (low consumers) ranged between 0 and $16 \%$ of energy and between 47 and $100 \%$ for quartile 4 (high consumers; Table 4). There were differences in sociodemographic, dietary and lifestyle factors between high and low consumers. More than half of low consumers were female (55.6\%) and the prevalence of females decreased with 
Table 3 Top five reported eating occasions (REO)* that contributed the most to total energy intake from discretionary foods and beverages (DF) and the top five sub-major food groups by percentage contribution to DF energy at each REO among Australian adults aged $\geq 19$ years $(n$ 9341) from the 2011-12 National Nutrition and Physical Activity Survey

${ }^{*}$ The remaining $25.3 \%$ of DF consumption came from breakfast $8.2 \%$, brunch $0.4 \%$, morning tea $4.4 \%$, afternoon tea $4.7 \%$, supper $2.7 \%$, extended consumption $4.6 \%$, and other $0.3 \%$. 
increasing quartile. DF intake decreased with age: 59.2\% of low consumers were aged 19-50 years, compared with $65.2 \%$ of high consumers. High consumers had a higher prevalence of adults from the lowest SES quintile compared with all other quartiles. There was a higher prevalence of low consumers who met physical activity guidelines based on duration and session: $46.5 \%$ of low consumers met guidelines, and this decreased with increasing quartile, of which $38.3 \%$ of high consumers met guidelines.

The prevalence of overweight and obese adults was not significantly different across quartiles of DF intake. Prevalence of no risk of chronic disease was significantly higher among low consumers (42.0\%) than among high consumers $(36 \cdot 1 \%)$.

The higher the quartile of DF energy, the higher the prevalence of smokers: $26 \%$ of high consumers were smokers compared with $12 \%$ of low consumers. Underreporting of energy intake was more prevalent among low consumers: 33\%, compared with 13\% among high consumers.

Based on general linear models adjusted for age, sex and their interaction, total daily energy and DF energy intake both increased with increasing quartile $(P<0.001)$, and high DF consumers had an average intake of $10 \cdot 1 \mathrm{DF}$ servings/d (Table 5). The number of daily EO was significantly lower among low consumers compared with the second and third quartiles $(P<0.001)$ but not among high consumers. The number of EO with DF increased across quartiles: high consumers had more than double the EO with DF compared with low consumers $(P<0 \cdot 001)$. Similarly, the proportion of EO that contained DF doubled from 34.4 (sE 0.4) \% among low consumers to 67.6 (SE $0 \cdot 4) \%$ among high consumers.

Low consumers had a higher number of minutes doing physical activity (236 (sE 6) min) than high consumers (189 (SE 6) $\mathrm{min}$ ) and spent less time sitting or lying down for work, transport and leisure ( $35 \mathrm{~h} 25 \mathrm{~min}$ ( $\mathrm{se} 27 \mathrm{~min}) v .38 \mathrm{~h}$ $20 \mathrm{~min}$ (se $29 \mathrm{~min}$ ); $P<0 \cdot 001$ ).

There was no significant difference in mean BMI; however, low consumers had a significantly lower waist circumference $(91.6(\mathrm{SE} 0.3) \mathrm{cm})$ than adults in quartile 3 $(93.4(\mathrm{SE} 0.3) \mathrm{cm})$ and high consumers $(93.9(\mathrm{SE} 0.3) \mathrm{cm}$; $P<0 \cdot 001)$.

Self-reported usual daily fruit servings decreased with increasing DF quartile, and high DF consumers selfreported fewer daily vegetable servings $(2 \cdot 2$ (SE 0.0)) than low consumers $(2 \cdot 4(\mathrm{SE} 0 \cdot 0))$ and those from the second quartile $(2.5$ (se 0.0$) ; P<0.001)$.

The top five food groups by DF energy contribution among low consumers were those consumed in smaller portion sizes such as sugar, honey and syrups and sweet biscuits (Table 6). In contrast, the top DF food groups among high consumers were those consumed in larger portion sizes, such as pastries, cakes and alcoholic beverages.
Results based on the same models are reported by age group and sex in the online supplementary material, Supplemental Table 2.

\section{Discussion}

The results of the present study demonstrate that virtually all Australian adults consumed DF, with an average intake of five DF servings; well above the maximum recommended three servings stipulated in the Australian Dietary Guidelines $^{(7)}$. DF intake varied by sex and age, with younger males having the highest intakes. Food groups that contributed the most to DF energy intake (cakes, muffins, scones, cake-type desserts; wines; pastries; beers) were characterised by large portion sizes. Lunch and dinner combined contributed almost half of daily DF energy intake, with pastries and wines, respectively, the most popular at those occasions. High DF consumption was correlated with lower SES, physical activity, usual fruit intake and higher waist circumference, but not higher BMI.

The high intake of DF by Australian adults is consistent with other national nutrition surveys globally. A high intake of $\mathrm{DF}$ as a proportion of total energy intake has been reported in studies in Belgium, the USA, Mexico and Canada. In Belgium, $92 \%$ of people aged 15 years or older consumed more than the maximum recommendation of less than $100 \mathrm{~g}$ of nutrient-poor, energy-dense foods daily $^{(26)}$. In the USA, energy-dense, nutrient-poor foods contributed $27 \%$ of total energy intake and alcohol contributed an additional $4 \%{ }^{(4)}$. In Mexico, results from the national nutrition survey for people aged 5 years or older reported that sugar-sweetened beverages and foods high in saturated fat and/or added sugars contributed $26 \%$ of total energy intake ${ }^{(27)}$; and in Canada, non-core foods contributed $22 \cdot 7 \%$ of total daily energy for adults ${ }^{(28)}$. Direct comparisons between countries are limited due the lack of a universal definition for DF and different methodologies in food classification $^{(29)}$. In Australia, an analysis of the 1995 National Nutrition Survey reported that $99 \%$ of adults consumed 'extra' foods and that these contributed $36 \%$ of total energy intake ${ }^{(5)}$. These findings suggest Australian DF intakes have largely remained unchanged since 1995, although there are minor differences in the definitions between 'extra foods' and 'discretionary foods' between the two surveys.

We found that young males were the highest consumers of DF, with more than half consuming five or more servings of DF in a day, similar to the previous 1995 National Nutrition Survey in Australia, where 19-24-year-old males had the highest percentage energy intake from 'extra' foods of all adults ${ }^{(5)}$. Similar findings have also been reported globally. In the USA, 19-30-year-old males were the most likely to exceed the daily maximum DF allowances $^{(30)}$; and in Canada, 19-30-year-old males, of all adult 
Table 4 Associations between quartiles of percentage energy contribution from discretionary foods and beverages (DF) and demographic, adiposity-related measures and lifestyle characteristics among Australian adults aged $\geq 19$ years ( $n$ 9341) from the 2011-12 National Nutrition and Physical Activity Survey

\begin{tabular}{|c|c|c|c|c|c|}
\hline & $\begin{array}{l}\text { Q1 (low } \\
\text { consumer) }\end{array}$ & Q2 & Q3 & $\begin{array}{l}\text { Q4 (high } \\
\text { consumer) }\end{array}$ & \multirow{3}{*}{$\begin{array}{c}P \text { value from Pearson's } X^{2} \\
\text { test }\end{array}$} \\
\hline Range of \% energy from DF & $0-16 \cdot 2$ & $16 \cdot 2-30 \cdot 6$ & $30 \cdot 6-46 \cdot 6$ & $46 \cdot 6-100$ & \\
\hline Characteristic & $\%$ & $\%$ & $\%$ & $\%$ & \\
\hline Sex (within quartile) & & & & & $<0.001$ \\
\hline Female & $55 \cdot 6$ & $52 \cdot 6$ & $48 \cdot 4$ & $45 \cdot 3$ & \\
\hline Male & $44 \cdot 4$ & $47 \cdot 4$ & $51 \cdot 6$ & $54 \cdot 7$ & \\
\hline Age group (within quartile) & & & & & $<0.001$ \\
\hline $19-30$ years & $22 \cdot 1$ & 21.9 & $22 \cdot 5$ & $26 \cdot 2$ & \\
\hline $31-50$ years & $37 \cdot 1$ & $37 \cdot 1$ & $36 \cdot 4$ & $39 \cdot 0$ & \\
\hline $51-70$ years & $30 \cdot 7$ & $29 \cdot 3$ & $28 \cdot 6$ & $25 \cdot 9$ & \\
\hline$\geq 71$ years & $10 \cdot 1$ & 11.7 & $12 \cdot 6$ & 8.9 & \\
\hline Age and sex groups (within quartile) & & & & & \\
\hline Females & & & & & $<0.001$ \\
\hline 19-30 years & $20 \cdot 6$ & $19 \cdot 8$ & $24 \cdot 1$ & 25.9 & \\
\hline $31-50$ years & $36 \cdot 4$ & $37 \cdot 4$ & $35 \cdot 7$ & $39 \cdot 4$ & \\
\hline $51-70$ years & $32 \cdot 1$ & $30 \cdot 1$ & $26 \cdot 4$ & $25 \cdot 2$ & \\
\hline$\geq 71$ years & $10 \cdot 8$ & $12 \cdot 7$ & 13.7 & 9.5 & \\
\hline Males & & & & & 0.025 \\
\hline 19-30 years & 23.9 & $24 \cdot 3$ & $20 \cdot 9$ & $26 \cdot 4$ & \\
\hline $31-50$ years & 38.0 & $36 \cdot 7$ & $37 \cdot 0$ & 38.6 & \\
\hline $51-70$ years & 28.9 & $28 \cdot 3$ & 30.5 & $26 \cdot 6$ & \\
\hline$\geq 71$ years & $9 \cdot 1$ & 10.6 & 11.5 & 8.4 & \\
\hline Quintiles SEIFA* (within quartile) & & & & & $<0.001$ \\
\hline Lowest $20 \%$ & $18 \cdot 0$ & $16 \cdot 4$ & $17 \cdot 4$ & $20 \cdot 6$ & \\
\hline Highest $20 \%$ & $23 \cdot 1$ & $24 \cdot 0$ & 21.7 & $19 \cdot 8$ & \\
\hline $\begin{array}{l}\text { Met physical activity guidelines } \\
\text { (duration and session) }\end{array}$ & $46 \cdot 5$ & $45 \cdot 5$ & $42 \cdot 7$ & $38 \cdot 3$ & $<0.001$ \\
\hline BMI group $\ddagger$ (within quartile) & & & & & 0.003 \\
\hline Underweight & $2 \cdot 2$ & $1 \cdot 3$ & $1 \cdot 3$ & $2 \cdot 3$ & \\
\hline Normal weight & 38.3 & 34.9 & 34.4 & $34 \cdot 1$ & \\
\hline Overweight & $35 \cdot 6$ & $35 \cdot 9$ & $37 \cdot 8$ & $36 \cdot 6$ & \\
\hline Obese & 23.9 & 27.9 & $26 \cdot 5$ & $27 \cdot 0$ & \\
\hline Waist circumference group§ (within quartile) & & & & & $<0.001$ \\
\hline No risk of chronic disease & $42 \cdot 0$ & $36 \cdot 4$ & $34 \cdot 7$ & $36 \cdot 1$ & \\
\hline Increased risk of chronic disease & $20 \cdot 9$ & 23.5 & $24 \cdot 5$ & $22 \cdot 6$ & \\
\hline $\begin{array}{l}\text { Substantially increased risk of chronic } \\
\text { disease }\end{array}$ & $37 \cdot 1$ & $40 \cdot 0$ & $40 \cdot 8$ & $41 \cdot 3$ & \\
\hline Current smoker (within quartile) & $12 \cdot 3$ & $14 \cdot 3$ & $19 \cdot 2$ & $25 \cdot 6$ & $<0.001$ \\
\hline Under-reporters \| (within quartile) & $32 \cdot 7$ & $21 \cdot 8$ & $17 \cdot 7$ & $13 \cdot 1$ & $<0.001$ \\
\hline
\end{tabular}

Q, quartile; SEIFA, Socio-Economic Indexes for Areas.

*SEIFA was developed by the Australian Bureau of Statistics and ranks areas in Australia according to their relative socio-economic advantage ${ }^{(21)}$. †For adults aged $\geq 18$ years, at least 150 min of physical activity over five or more sessions per week is recommended ${ }^{(20)}$.

†Based on BMl: underweight $\left(<18.5 \mathrm{~kg} / \mathrm{m}^{2}\right)$; normal weight $\left(\geq 18.5-<25.0 \mathrm{~kg} / \mathrm{m}^{2}\right)$; overweight $\left(\geq 25 \cdot 0-<30.0 \mathrm{~kg} / \mathrm{m}^{2}\right)$; obese $\left(\geq 30 \cdot 0 \mathrm{~kg} / \mathrm{m}^{2}\right)^{(22)}$.

§Based on WHO cut-offs for waist circumference: not at risk of metabolic complications ( $<80 \mathrm{~cm}$ for females, $<94 \mathrm{~cm}$ for males); increased risk of metabolic complications ( $\geq 80$ and $<88 \mathrm{~cm}$ for females, $\geq 94$ and $<102 \mathrm{~cm}$ for males); substantially increased risk of metabolic complications ( $\geq 88 \mathrm{~cm}$ for females, $\geq 102 \mathrm{~cm}$ for males) $)^{(23}$.

$\|$ Participants were classified as under-reporters based on the Goldberg cut-off limit of an energy intake to BMR ratio of 0.9(24).

groups, consumed the greatest percentage of energy from 'other foods' outside the four main food groups ${ }^{(28)}$. Compared with females, males are less likely to have a high level of nutrition knowledge ${ }^{(31)}$, are less likely to be health conscious $^{(32,33)}$ and are less likely to be involved in meal preparation $^{(34)}$. Since eating behaviour can persist into later life ${ }^{(35-37)}$, there is a need for the development of DFreducing interventions that target younger males.

Our analysis found that the top food groups that contributed to DF energy intake each had high mean DF servings per consumer, at quantities close or equal to three DF servings, the maximum recommended for an entire day $^{(7)}$. Interestingly, the most popular DF food groups - including sugar, honey and syrups; sweet biscuits; and soft drinks and flavoured mineral waters - were not among the highest contributors to DF energy intake as they had much smaller portion sizes. These smaller portion-sized food groups were more likely to be the top DF energy contributors among low DF consumers. However, the top food groups among high consumers were foods typically consumed in larger portion sizes. It is likely that portion sizes are an important contributing factor to high DF intake. There is considerable evidence that the portion sizes of many foods, particularly DF, have increased in the $\mathrm{USA}^{(38,39)}$, the Netherlands ${ }^{(40)}$ and $\operatorname{Australia}^{(15)}$, and it is well established that increasing portion size increases 


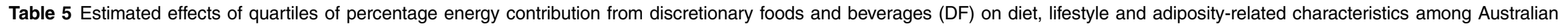
adults aged $\geq 19$ years $(n$ 9341) from the 2011-12 National Nutrition and Physical Activity Survey

\begin{tabular}{|c|c|c|c|c|c|c|c|c|c|}
\hline \multirow[b]{2}{*}{ Characteristic* $^{*}$} & \multicolumn{2}{|c|}{ Q1 (low consumer) } & \multicolumn{2}{|c|}{ Q2 } & \multicolumn{2}{|c|}{ Q3 } & \multicolumn{2}{|c|}{ Q4 (high consumer) } & \multirow[b]{2}{*}{$P$ value $\dagger$} \\
\hline & Mean & SE & Mean & SE & Mean & $\mathrm{SE}$ & Mean & $\mathrm{SE}$ & \\
\hline Energy intake $(\mathrm{MJ}) \ddagger$ & $7 \cdot 5^{\mathrm{a}}$ & 0.1 & $8 \cdot 3^{b}$ & 0.1 & $8 \cdot 7^{\mathrm{C}}$ & $0 \cdot 1$ & $9 \cdot 6^{\mathrm{d}}$ & 0.1 & $<0.001$ \\
\hline DF energy intake (MJ)‡ & $0.6^{\mathrm{a}}$ & 0.03 & $2 \cdot 0^{\mathrm{b}}$ & 0.03 & $3 \cdot 4^{\mathrm{C}}$ & 0.03 & $6 \cdot 0^{\mathrm{d}}$ & 0.03 & $<0.001$ \\
\hline Non-DF energy intake (MJ)‡ & $6 \cdot 8^{\mathrm{a}}$ & 0.05 & $6 \cdot 3^{b}$ & 0.05 & $5 \cdot 3^{\mathrm{c}}$ & 0.05 & $3 \cdot 6^{d}$ & 0.05 & $<0.001$ \\
\hline Proportion of energy from DF (\%)§ & $8 \cdot 3^{\mathrm{a}}$ & 0.1 & $24 \cdot 1^{\mathrm{b}}$ & 0.1 & $39.0^{\mathrm{C}}$ & 0.1 & $61 \cdot 7^{\mathrm{d}}$ & 0.2 & $<0.001$ \\
\hline DF servings $\ddagger$ & $1 \cdot 1^{\mathrm{a}}$ & 0.05 & $3 \cdot 3^{\mathrm{b}}$ & 0.05 & $5 \cdot 7^{\mathrm{c}}$ & 0.06 & $10 \cdot 1^{\mathrm{d}}$ & 0.06 & $<0.001$ \\
\hline Total EO\| & $6 \cdot 6^{\mathrm{a}}$ & 0.05 & $7.0^{\mathrm{b}}$ & 0.05 & $7 \cdot 1^{\mathrm{b}}$ & 0.05 & $6 \cdot 9^{\mathrm{a}, \mathrm{b}}$ & 0.05 & $<0.001$ \\
\hline EO with DF\| & $2 \cdot 2^{\mathrm{a}}$ & 0.03 & $3.4^{b}$ & 0.03 & $4 \cdot 1^{\mathrm{c}}$ & 0.03 & $4.5^{\mathrm{d}}$ & 0.04 & $<0.001$ \\
\hline Proportion of EO with DF (\%)\| & $34 \cdot 4^{\mathrm{a}}$ & 0.4 & $50 \cdot 5^{\mathrm{b}}$ & 0.4 & $59 \cdot 7^{\mathrm{C}}$ & 0.4 & $67 \cdot 6^{\mathrm{d}}$ & 0.4 & $<0.001$ \\
\hline Physical activity (min) $\ddagger$ & $236^{\mathrm{a}}$ & 6 & $217^{a, b, c}$ & 6 & $229^{b}$ & 6 & $189^{\circ}$ & 6 & $<0.001$ \\
\hline Time sitting or lying down for work, transport and leisure $(\min ) \ddagger$ & $2125^{a}$ & 27 & $2261^{a, b}$ & 27 & $2344^{\mathrm{b}}$ & 28 & $2300^{\mathrm{b}}$ & 29 & $<0.001$ \\
\hline BMI $\left(\mathrm{kg} / \mathrm{m}^{2}\right) \|$ & 26.9 & 0.1 & $27 \cdot 3$ & 0.1 & $27 \cdot 4$ & 0.1 & $27 \cdot 4$ & 0.1 & 0.014 \\
\hline Waist circumference $(\mathrm{cm}) \|$ & $91 \cdot 6^{\mathrm{a}}$ & 0.3 & $92 \cdot 8^{\mathrm{a}, \mathrm{b}}$ & 0.3 & $93 \cdot 4^{\mathrm{b}}$ & 0.3 & $93.9^{\mathrm{b}}$ & 0.3 & $<0.001$ \\
\hline Self-reported fruit servings $\|$ & $1.9^{\mathrm{a}}$ & 0.02 & $1.8^{\mathrm{b}}$ & 0.02 & $1.6^{\mathrm{c}}$ & 0.02 & $1.4^{\mathrm{d}}$ & 0.02 & $<0.001$ \\
\hline Self-reported vegetable servings\| & $2 \cdot 4^{\mathrm{a}}$ & 0.03 & $2 \cdot 5^{\mathrm{a}}$ & 0.03 & $2 \cdot 3^{\mathrm{a}, \mathrm{b}}$ & 0.03 & $2 \cdot 2^{\mathrm{b}}$ & 0.03 & $<0.001$ \\
\hline
\end{tabular}

$\mathrm{Q}$, quartile; EO, eating occasion.

a,b,c,d Mean values within a row with unlike superscript letters were significantly different $(P<0.001$ post hoc, Bonferroni).

${ }^{*}$ Adjusted for quartile of percentage energy from DF, age group, sex and their interaction using univariate ANOVA.

†Univariate ANOVA denote the effect of quartiles of percentage energy from DF.

łAge group, sex and their interaction were all significant $(P<0.001$, univariate ANOVA).

No variables (apart from quartile percentage of energy from DF) were significant in the model (univariate ANOVA)

Age group and sex were significant $(P<0.001)$ but not their interaction (univariate ANOVA) 
Table 6 Top five sub-major food groups by quartiles of percentage energy contribution from discretionary foods and beverages among Australian adults aged $\geq 19$ years ( $n$ 9341) from the 2011-12 National Nutrition and Physical Activity Survey

\begin{tabular}{|c|c|c|c|c|c|c|c|c|}
\hline \multirow[b]{2}{*}{ Rank } & \multicolumn{2}{|c|}{ Q1 (low consumer) } & \multicolumn{2}{|c|}{ Q2 } & \multicolumn{2}{|c|}{ Q3 } & \multicolumn{2}{|c|}{ Q4 (high consumer) } \\
\hline & $\begin{array}{l}\text { Sub-major food } \\
\text { group }\end{array}$ & $\begin{array}{l}\text { Contribution } \\
\text { to total } \\
\text { energy intake } \\
(\%)\end{array}$ & $\begin{array}{l}\text { Sub-major food } \\
\text { group }\end{array}$ & $\begin{array}{c}\text { Contribution } \\
\text { to total } \\
\text { energy intake } \\
(\%)\end{array}$ & $\begin{array}{l}\text { Sub-major food } \\
\text { group }\end{array}$ & $\begin{array}{l}\text { Contribution } \\
\text { to total } \\
\text { energy intake } \\
(\%)\end{array}$ & $\begin{array}{l}\text { Sub-major food } \\
\text { group }\end{array}$ & $\begin{array}{c}\text { Contribution } \\
\text { to total } \\
\text { energy intake } \\
(\%)\end{array}$ \\
\hline 1. & $\begin{array}{r}\text { Sugar, honey } \\
\text { and syrups }\end{array}$ & $1 \cdot 1$ & Wines & $2 \cdot 4$ & $\begin{array}{l}\text { Cakes, muffins, } \\
\text { scones, } \\
\text { cake-type } \\
\text { desserts }\end{array}$ & $3 \cdot 7$ & Pastries & $6 \cdot 2$ \\
\hline 2. & Sweet biscuits & 0.7 & Sweet biscuits & $1 \cdot 8$ & Wines & $3 \cdot 4$ & $\begin{array}{l}\text { Cakes, muffins, } \\
\text { scones, } \\
\text { cake-type } \\
\text { desserts }\end{array}$ & 5.5 \\
\hline 3. & Processed meat & 0.5 & $\begin{array}{l}\text { Sugar, honey } \\
\text { and syrups }\end{array}$ & $1 \cdot 6$ & Pastries & $3 \cdot 0$ & Wines & 4.5 \\
\hline 4. & Salad dressings & 0.4 & $\begin{array}{l}\text { Cakes, muffins, } \\
\text { scones, cake- } \\
\text { type desserts }\end{array}$ & 1.6 & Beers & $2 \cdot 4$ & Beers & $4 \cdot 3$ \\
\hline 5. & $\begin{array}{l}\text { Chocolate and } \\
\text { chocolate- } \\
\text { based } \\
\text { confectionery }\end{array}$ & 0.4 & $\begin{array}{l}\text { Chocolate and } \\
\text { chocolate- } \\
\text { based } \\
\text { confectionery }\end{array}$ & 1.3 & $\begin{array}{l}\text { Soft drinks, and } \\
\text { flavoured } \\
\text { mineral } \\
\text { waters }\end{array}$ & $2 \cdot 1$ & $\begin{array}{l}\text { Soft drinks, and } \\
\text { flavoured } \\
\text { mineral } \\
\text { waters }\end{array}$ & $3 \cdot 2$ \\
\hline
\end{tabular}

Q, quartile.

energy intake in well-controlled laboratory studies ${ }^{(41-44)}$. Beverages may be of particular concern among high DF consumers. Three of the leading five food group contributors to DF energy intake among adults in the third and fourth quartiles of DF intake were beverages, compared with low DF consumers, who had no beverages in the leading five DF contributors. It has been demonstrated that beverages have a relatively low satiety value in comparison to solid foods ${ }^{(45-47)}$. Experimental evidence has shown that a reduction in portion size leads to a reduction in energy intake ${ }^{(48)}$, including for discretionary foods ${ }^{(49)}$, even when there is no change to the total quantity of food offered $^{(50)}$. Strategies to reduce DF consumption should therefore consider interventions that reduce portion size, such as the use of visual cues, labelling, reducing the size of packaging and plate size ${ }^{(51)}$. Selecting discretionary foods that are generally consumed in smaller portions, such as sugar, honey and syrups in coffee or tea, or processed meat in a sandwich, instead of those consumed in larger portions, such as cakes, muffins, scones, cake-type desserts or pastries, may also help to reduce total DF energy intake, since it may be more difficult to have smaller portions of the latter foods, such as a quarter of a piece of cake or half a muffin. Given that there is high variability in the manufacturer-declared serving sizes for DF in Australia ${ }^{(52)}$, and that inaccurate estimation of standard dietary servings and portion sizes may also contribute to excess consumption ${ }^{(53)}$, reference guidelines or regulatory policy concerning the development and labelling of serving sizes for DF should also be considered.

We found that dinner, lunch, snack and beverage/ drink were the four leading EO that contributed to DF energy intake, with dinner and lunch combined contributing almost half of daily DF energy intake. Few studies have previously investigated the contribution of EO to DF energy intake ${ }^{(54)}$. In Mexico, the proportion of energy that products high in saturated fat and/or high in added sugar contributed was higher at mid-afternoon snacks and lower at lunch and brunch, while the proportion of energy from sugar-sweetened beverages was higher during mid-morning snacks ${ }^{(55)}$. In Australia, an analysis of the 2011-12 NNPAS reported that a higher frequency of snacks (self-reported by participants), but not main meals, was associated with a lower compliance to the Dietary Guidelines Index for discretionary foods ${ }^{(56)}$. In our analysis, the REO snack contributed a high percentage of DF energy, but morning tea, afternoon tea and supper, which traditionally are also snacking occasions, did not. With more than half of all EO containing DF, encouraging adults to have EO free of DF may help to reduce its consumption.

Targeting high-DF EO with the provision of core foods may also be an effective means for reducing DF intake at these meal times, since the substitution of discretionary with core foods has been shown to reduce energy intake ${ }^{(49)}$. In a crossover trial that incorporated vegetables in place of other ingredients within a recipe to lower the energy density of the entire meal, intake of vegetables increased and reduced the total energy intake over the day, without changes to satiety ${ }^{(57)}$. In a national nutrition campaign in the UK, the promotion of 'smart swaps', or the replacement of discretionary foods with core foods, was associated with a change in purchase habits towards healthier products ${ }^{(58)}$.

Wines was the top food group at dinner and beers the top at beverage/drink that contributed to DF energy 
intake. The high energy contribution from alcohol is consistent with data that show alcohol consumption in Australia is among the highest in the world ${ }^{(59)}$. Alcohol is a top source of discretionary energy and, unlike other discretionary foods, can be an addictive drug ${ }^{(60)}$; since it is not necessary to meet nutritional needs, its reduction should be a top public health priority. The high contribution of alcoholic beverages to total DF energy intake reinforces the need for DF-reducing strategies to specifically target a reduction in alcohol intake.

We found that foods and beverages that were top sources of discretionary energy were not necessarily the top sources of the nutrients total sugars, saturated fat and Na. For example: wines, pastries and beers were among the leading contributors to DF energy but not to total sugars intake; and sugar, honey and syrups was among the leading contributors to total sugars intake but not DF energy intake. It should be noted, however, that these outcomes may have differed if added sugars had been analysed instead of total sugars although, by definition, total sugars from discretionary foods are mostly added. These findings suggest that it is a combination of portion size and the type of food that influences discretionary energy intake, and hence a focus on individual nutrients alone is unlikely to target the leading contributors to total DF energy intake in the diet of Australian adults. Our data strengthen the case for interventions aimed at reducing DF consumption that focus on targeted EO and whole diets rather than on singular nutrients of concern.

Compared with low consumers, high consumers were more likely to report lower physical activity, be a current smoker and have a lower usual fruit intake. The clustering of high DF intake with other less healthy lifestyle behaviours, such as lower physical activity and greater fastfood intake, has been previously reported in the USA ${ }^{(11)}$. Data from the National Health and Nutrition Examination Survey (NHANES) also reported that a high intake of energy-dense, nutrient-poor foods was associated with a low intake of core foods ${ }^{(4)}$. Interventions that appreciate these interrelationships may be more effective than interventions aimed at reducing DF alone.

Consistent with our finding, there is a large body of evidence that reports an association between lower SES and poorer diet quality ${ }^{(61)}$, including in Australia ${ }^{(62)}$, but these findings are not uniform across countries. High DF intake has been associated with a higher SES in Mexico ${ }^{(27)}$ and a lower DF intake has been associated with lower income earners in the $\mathrm{USA}^{(4)}$. Since the relationship between diet quality and SES may differ according to the culture and economic status of the country, it is important to have population-specific data to best inform local intervention policies aimed at reducing DF intake. In Australia females of low SES reported that the perceived high cost of healthy food and a lack of time were important barriers for healthy eating ${ }^{(63)}$. Yet, it has been shown that healthy diets can be more affordable than current (less healthy) diets in Australia ${ }^{(64)}$ and that an education-based intervention on food affordability improves perceptions of healthy food affordability in Australian mothers ${ }^{(65)}$. Reducing the perception of the high cost and time commitments associated with healthy eating may be particularly important for reducing DF intake.

With respect to adiposity-related measures, we found a clear and consistent relationship with DF consumption and waist circumference, but not BMI. There is a large body of evidence that waist circumference independent of BMI is a significant predictor of chronic diseases ${ }^{(66-69)}$. An association between DF or its components and waist circumference, but not BMI, has been reported previously. An analysis of the 1988-1994 NHANES reported that high waist circumference but not BMI was associated with the amount of daily energy intake from energy-dense, nutrient-poor foods in men ${ }^{(4)}$. An increase in waist circumference but not BMI was also associated with increasing frequency of sugar-sweetened beverage intake in a study of US adults ${ }^{(70)}$. A number of prospective studies that measured increases in waist circumference adjusted for BMI have also reported an association with poorer diet quality $^{(71-74)}$. Increased waist circumference without changes to BMI may be a marker of increased visceral fat, and it has been suggested that some aspects of poor diet quality, such as high glycaemic index, may causally encourage greater visceral fat storage ${ }^{(72,75)}$. It is also possible that our observed associations are due to confounding factors or under-reporting. In our study, low DF consumers were more likely to meet recommendations for physical activity, for example, which generally reduces abdominal fat ${ }^{(76)}$. We also found a substantially higher proportion of under-reporting among the lowest consumers of DF (33\%) compared with the highest consumers of DF (13\%). This may be explained in part by a proportion of low DF consumers actively dieting and purposely reducing total energy and DF intake, and not under-reporting as predicted by EI:BMR. Overweight and obese individuals are more likely to under-report than lean individuals $^{(77)}$ and DF are more likely to be underreported than other foods ${ }^{(78,79)}$. Intervention studies are required to better understand the possible causal effects between different DF and the different measures of adiposity.

A particular strength of the present study is the use of a large, nationally representative sample of the Australian adult population. The data are cross-sectional and causal effects cannot be determined from the observed associations. Dietary intake was derived from a single day of $24 \mathrm{~h}$ recall and is not indicative of usual intakes. Two-thirds of respondents in the NNPAS provided two days of recall; however, in order to maximise the sample size only day 1 of recall was used. Evidence of under-reporting of energy intake in the survey implies that total DF intake could be 
even higher than reported. Since under-reporting is generally higher in females and overweight and obese respondents ${ }^{(77)}$, under-reporting may have also impacted the observed associations between DF intake and other variables, such as sex, waist circumference and BMI.

\section{Conclusions}

In summary, the current results showed intakes of DF well above the maximum recommended levels stipulated by the Australian Dietary Guidelines, with the average per capita intake equivalent to five DF servings daily. The leading contributors to total DF energy intake were generally DF food groups consumed in large portion sizes, close or equal to three DF servings, the maximum DF energy limit recommended for an entire day. Dinner and lunch were the leading contributors to DF energy intake of all EO and contributed almost half of all DF energy intake, followed by the REO snack and beverage/ drink. Addressing high DF intake by targeting the DF consumed in large portion sizes, particularly at dinner and lunch, may help to inform more strategic and evidenced-based DF-reducing interventions, for which the need is compelling.

\section{Acknowledgements}

Acknowledgements: The authors would like to thank the Australian Bureau of Statistics for conducting the survey. Financial support: Funding for this research was provided to Nutrition Research Australia by Nestlé Australia. J.K., an employee of Nestlé Australia, assisted with editing of the manuscript. The funding sponsors had no role in the design of the study; in the analyses or interpretation of data; or in the decision to publish the results. Conflict of interest: J.K. is an employee of Nestlé Australia, which provided study funding. All other authors declared no conflict of interest. Authorship: F.F.-M developed the research plan and had primary responsibility for the analysis and final content. A.M. and P.P were responsible for the data and statistical analyses. All authors assisted with the manuscript writing and have read and approved the final manuscript. Ethics of buman subject participation: Not applicable as the study was a secondary analysis of existing national survey data. The Australian Bureau of Statistics collected the data under the Census and Statistics Act 1905.

\section{Supplementary material}

To view supplementary material for this article, please visit https://doi.org/10.1017/S1368980018003361

\section{References}

1. National Health and Medical Research Council (2013) Australian Dietary Guidelines. Canberra: NHMRC; available at https://nhmrc.gov.au/about-us/publications/australian-diet ary-guidelines

2. National Health and Medical Research Council \& Department of Health (2017) Eat for Health I Discretionary food and drink choices. https://www.eatforhealth.gov.au/foodessentials/discretionary-food-and-drink-choices (accessed November 2018).

3. Albar SA, Alwan NA, Evans CE et al. (2014) Is there an association between food portion size and BMI among British adolescents? Br J Nutr 112, 841-51.

4. Kant AK (2000) Consumption of energy-dense, nutrientpoor foods by adult Americans: nutritional and health implications. The third National Health and Nutrition Examination Survey, 1988-1994. Am J Clin Nutr 72, 929-936.

5. Rangan AM, Schindeler S, Hector DJ et al. (2009) Consumption of 'extra' foods by Australian adults: types, quantities and contribution to energy and nutrient intakes. Eur J Clin Nutr 63, 865-871.

6. Reedy J \& Krebs-Smith SM (2010) Dietary sources of energy, solid fats, and added sugars among children and adolescents in the United States. J Am Diet Assoc 110, 1477-1484.

7. National Health and Medical Research Council \& Department of Health and Ageing (2013) Eat for Health Educator Guide: Information for Nutrition Educators. Canberra: NHMRC; available at https://www.eatforhealth.gov.au/sites/ default/files/files/the_guidelines/n55b_eat_for_health_educa tors_guide.pdf

8. Cohen DA, Sturm R, Lara M et al. (2010) Discretionary calorie intake a priority for obesity prevention: results of rapid participatory approaches in low-income US communities. J Public Health (Oxf) 32, 379-386.

9. Ledikwe JH, Blanck HM, Kettel Khan L et al. (2006) Dietary energy density is associated with energy intake and weight status in US adults. Am J Clin Nutr 83, 1362-1368.

10. Ma J, Fox CS, Jacques PF et al. (2015) Sugar-sweetened beverage, diet soda, and fatty liver disease in the Framingham Heart Study cohorts. J Hepatol 63, 462-469.

11. Pereira MA, Kartashov AI, Ebbeling CB et al. (2005) Fastfood habits, weight gain, and insulin resistance (the CARDIA study): 15-year prospective analysis. Lancet 365, 36-42.

12. Australian Bureau of Statistics (2015) National Health Survey: First Results, 2014-15. Catalogue no. 4364.0.55.001. Canberra: ABS; available at http://www.abs.gov.au/ausstats/ abs@.nsf/mf/4364.0.55.001

13. Australian Institute of Health and Welfare (2014) Australia's Health 2014. Australia's Health Series no. 14. Catalogue no. AUS 178. Canberra: AIHW; available at https://www.aihw. gov.au/reports/australias-health/australias-health-2014/cont ents/table-of-contents

14. Australian Bureau of Statistics (2014) Australian Health Survey: Nutrition First Results - Foods and Nutrients, 201112. Catalogue no. 4364.0.55.007. Canberra: ABS; available at http://www.abs.gov.au/ausstats/abs@.nsf/Lookup/ 4364.0.55.007main+features12011-12

15. Zheng M, Wu JH, Louie JC et al. (2016) Typical food portion sizes consumed by Australian adults: results from the 2011-12 Australian National Nutrition and Physical Activity Survey. Sci Rep 6, 19596.

16. Australian Bureau of Statistics (2016) Australian Health Survey: Consumption of Food Groups from the Australian Dietary Guidelines, 2011-12. Catalogue no. 4364.0.55.011. Canberra: ABS; available at http://www.abs.gov.au/ausstats/ abs@.nsf/Lookup/4364.0.55.012main+features12011-12

17. Piernas C, Wang D, Du S et al. (2015) The double burden of under- and overnutrition and nutrient adequacy among 
Chinese preschool and school-aged children in 2009-2011. Eur J Clin Nutr 69, 1323-1329.

18. Bliss R (2004) Researchers produce innovation in dietary recall. Agric Res 52, June issue, 10-12; available at http:// www.ars.usda.gov/is/AR/archive/jun04/recall0604.pdf

19. Food Standards Australia New Zealand (2010) NUTTAB 2010 Online Searchable Database. http://www.foodstandards. gov.au/science/monitoringnutrients/nutrientables/Pages/default. aspxx (accessed January 2019).

20. Australian Bureau of Statistics (2013) Australian Health Survey: Users' Guide, 2011-13. Catalogue no. 4363.0.55.001. Canberra: ABS; available at http://www.abs. gov.au/ausstats/abs@.nsf/mf/4363.0.55.001

21. Australian Bureau of Statistics (2009) Perspectives on Education and Training: Social Inclusion. Catalogue no. 4250.0.55.001. Canberra: ABS; available at http://www.abs. gov.au/ausstats/abs@.nsf/mf/4250.0.55.001

22. World Health Organization (2000) Obesity: Preventing and Managing the Global Epidemic. Report of a WHO Consultation. WHO Technical Report Series no. 894. Geneva: WHO; available at http://www.who.int/nutrition/publica tions/obesity/WHO_TRS_894/en/

23. World Health Organization (2011) Waist Circumference and Waist-Hip Ratio. Report of a WHO Expert Consultation, Geneva, 8-11 December 2008. Geneva: WHO; available at http://www.who.int/nutrition/publications/obesity/ WHO_report_waistcircumference_and_waisthip_ratio/en/

24. Goldberg GR, Black AE, Jebb SA et al. (1991) Critical evaluation of energy intake data using fundamental principles of energy physiology: 1. Derivation of cut-off limits to identify under-recording. Eur J Clin Nutr 45, 569-81.

25. National Health and Medical Research Council \& Department of Health and Ageing (2011) A Modelling System to Inform the Revision of the Australian Guide to Healthy Eating. Canberra: NHMRC; available at https://www.eat forhealth.gov.au/sites/default/files/files/public_consultation/ n55a_dietary_guidelines_food_modelling_111216.pdf

26. Vandevijvere S, De Vriese S, Huybrechts I et al. (2009) The gap between food-based dietary guidelines and usual food consumption in Belgium, 2004. Public Health Nutr 12, 423-431.

27. Aburto TC, Pedraza LS, Sanchez-Pimienta TG et al. (2016) Discretionary foods have a high contribution and fruit, vegetables, and legumes have a low contribution to the total energy intake of the Mexican population. J Nutr 146, issue 9, 1881S-1887S.

28. Garriguet D (2007) Canadians' eating habits. Health Rep 18, $17-32$.

29. Auestad N, Hurley JS, Fulgoni VL 3rd et al. (2015) Contribution of food groups to energy and nutrient intakes in five developed countries. Nutrients 7, 4593-4618.

30. Krebs-Smith SM, Guenther PM, Subar AF et al. (2010) Americans do not meet federal dietary recommendations. J Nutr 140, 1832-1838.

31. Worsley A, Wang WC, Byrne S et al. (2014) Different patterns of Australian adults' knowledge of foods and nutrients related to metabolic disease risk. J Nutr Sci 3, e14.

32. Fagerli RA \& Wandel M (1999) Gender differences in opinions and practices with regard to a 'healthy diet'. Appetite 32, 171-190.

33. von Bothmer MI \& Fridlund B (2005) Gender differences in health habits and in motivation for a healthy lifestyle among Swedish university students. Nurs Health Sci 7, 107-118.

34. Smith KJ, McNaughton SA, Gall SL et al. (2010) Involvement of young Australian adults in meal preparation: crosssectional associations with sociodemographic factors and diet quality. J Am Diet Assoc 110, 1363-1367.

35. Larson NI, Neumark-Sztainer DR, Story MT et al. (2008) Fast food intake: longitudinal trends during the transition to young adulthood and correlates of intake. $J$ Adolesc Health 43, 79-86.

36. Lipsky LM, Haynie DL, Liu D et al. (2015) Trajectories of eating behaviors in a nationally representative cohort of US adolescents during the transition to young adulthood. Int $J$ Behav Nutr Phys Act 12, 138

37. Pedersen TP, Holstein BE, Flachs EM et al. (2013) Meal frequencies in early adolescence predict meal frequencies in late adolescence and early adulthood. BMC Public Health 13, 445 .

38. Nielsen SJ \& Popkin BM (2003) Patterns and trends in food portion sizes, 1977-1998. JAMA 289, 450-453.

39. Young LR \& Nestle M (2002) The contribution of expanding portion sizes to the US obesity epidemic. Am J Public Health 92, 246-249.

40. Steenhuis IH, Leeuwis FH \& Vermeer WM (2010) Small, medium, large or supersize: trends in food portion sizes in The Netherlands. Public Health Nutr 13, 852-857.

41. Ello-Martin JA, Ledikwe JH \& Rolls BJ (2005) The influence of food portion size and energy density on energy intake: implications for weight management. Am J Clin Nutr 82, 1 Suppl., 236S-241S.

42. Rolls BJ, Morris EL \& Roe LS (2002) Portion size of food affects energy intake in normal-weight and overweight men and women. Am J Clin Nutr 76, 1207-1213.

43. Rolls BJ, Roe LS \& Meengs JS (2006) Reductions in portion size and energy density of foods are additive and lead to sustained decreases in energy intake. Am J Clin Nutr $\mathbf{8 3}$, $11-17$.

44. Kral TV, Roe LS \& Rolls BJ (2004) Combined effects of energy density and portion size on energy intake in women. Am J Clin Nutr 79, 962-968.

45. Cassady BA, Considine RV \& Mattes RD (2012) Beverage consumption, appetite, and energy intake: what did you expect? Am J Clin Nutr 95, 587-593.

46. Leidy HJ, Apolzan JW, Mattes RD et al. (2010) Food form and portion size affect postprandial appetite sensations and hormonal responses in healthy, nonobese, older adults. Obesity (Silver Spring) 18, 293-299.

47. Mattes RD \& Campbell WW (2009) Effects of food form and timing of ingestion on appetite and energy intake in lean young adults and in young adults with obesity. J Am Diet Assoc 109, 430-437.

48. Stroebele N, Ogden LG \& Hill JO (2009) Do caloriecontrolled portion sizes of snacks reduce energy intake? Appetite 52, 793-796.

49. Grieger JA, Wycherley TP, Johnson BJ et al. (2016) Discrete strategies to reduce intake of discretionary food choices: a scoping review. Int J Behav Nutr Phys Act 13, 57.

50. Marchiori D, Waroquier L \& Klein O (2011) Smaller food item sizes of snack foods influence reduced portions and caloric intake in young adults. J Am Diet Assoc 111, $727-731$

51. Benton D (2015) Portion size: what we know and what we need to know. Crit Rev Food Sci Nutr 55, 988-1004.

52. Haskelberg H, Neal B, Dunford E et al. (2016) High variation in manufacturer-declared serving size of packaged discretionary foods in Australia. Br J Nutr 115, 1810-1818.

53. Abramovitch SL, Reddigan JI, Hamadeh MJ et al. (2012) Underestimating a serving size may lead to increased food consumption when using Canada's Food Guide. Appl Physiol Nutr Metab 37, 923-930.

54. Leech RM, Worsley A, Timperio A et al. (2015) Understanding meal patterns: definitions, methodology and impact on nutrient intake and diet quality. Nutr Res Rev $\mathbf{2 8}$, $1-21$.

55. Batis C, Rodriguez-Ramirez S, Ariza AC et al. (2016) Intakes of energy and discretionary food in Mexico are associated with the context of eating: mealtime, activity, and place. $J$ Nutr 146, issue 9, 1907S-1915S. 
56. Leech RM, Livingstone KM, Worsley A et al. (2016) Meal frequency but not snack frequency is associated with micronutrient intakes and overall diet quality in Australian men and women. $J$ Nutr 146, 2027-2034.

57. Blatt AD, Roe LS \& Rolls BJ (2011) Hidden vegetables: an effective strategy to reduce energy intake and increase vegetable intake in adults. Am J Clin Nutr $\mathbf{9 3}$ 756-763.

58. Wrieden WL \& Levy LB (2016) 'Change4Life Smart Swaps': quasi-experimental evaluation of a natural experiment. Public Health Nutr 19, 2388-2392.

59. World Health Organization (2009) World Health Statistics 2009. Geneva: WHO; available at http://www.who.int/ whosis/whostat/2009/en/

60. National Health and Medical Research Council (2009) Australian Guidelines to Reduce Health Risks from Drinking Alcohol. Canberra: NHMRC; available at https://nhmrc.gov. au/about-us/publications/australian-guidelines-reduce-healthrisks-drinking-alcohol

61. Darmon N \& Drewnowski A (2008) Does social class predict diet quality? Am J Clin Nutr 87, 1107-1117.

62. Grech A, Sui Z, Siu HY et al. (2017) Socio-demographic determinants of diet quality in Australian adults using the validated Healthy Eating Index for Australian Adults (HEIFA-2013). Healthcare (Basel) 5, E7.

63. Inglis V, Ball K \& Crawford D (2005) Why do women of low socioeconomic status have poorer dietary behaviours than women of higher socioeconomic status? A qualitative exploration. Appetite 45, 334-343.

64. Lee AJ, Kane S, Ramsey R et al. (2016) Testing the price and affordability of healthy and current (unhealthy) diets and the potential impacts of policy change in Australia. BMC Public Health 16, 315.

65. Williams LK, Abbott G, Thornton LE et al. (2014) Improving perceptions of healthy food affordability: results from a pilot intervention. Int J Behav Nutr Phys Act 11, 33.

66. Elbassuoni E (2013) Better association of waist circumference with insulin resistance and some cardiovascular risk factors than body mass index. Endocr Regul 47, 3-14.

67. Janssen I, Katzmarzyk PT \& Ross R (2004) Waist circumference and not body mass index explains obesityrelated health risk. Am J Clin Nutr 79, 379-384.
68. Leitzmann MF, Moore SC, Koster A et al. (2011) Waist circumference as compared with body-mass index in predicting mortality from specific causes. PLoS One 6, e18582.

69. Pischon T, Boeing H, Hoffmann K et al. (2008) General and abdominal adiposity and risk of death in Europe. $N$ Engl $J$ Med 359, 2105-2120.

70. Odegaard AO, Choh AC, Czerwinski SA et al. (2012) Sugarsweetened and diet beverages in relation to visceral adipose tissue. Obesity (Silver Spring) 20, 689-691.

71. Halkjaer J, Sorensen TI, Tjonneland A et al. (2004) Food and drinking patterns as predictors of 6-year BMI-adjusted changes in waist circumference. Br J Nutr 92, 735-748.

72. Romaguera D, Angquist L, Du H et al. (2010) Dietary determinants of changes in waist circumference adjusted for body mass index - a proxy measure of visceral adiposity. PLoS One 5, e11588.

73. Romaguera D, Angquist L, Du H et al. (2011) Food composition of the diet in relation to changes in waist circumference adjusted for body mass index. PLoS One 6, e23384.

74. Romaguera D, Norat T, Mouw T et al. (2009) Adherence to the Mediterranean diet is associated with lower abdominal adiposity in European men and women. $J$ Nutr 139, $1728-1737$.

75. Du H, van der A DL, van Bakel MM et al. (2009) Dietary glycaemic index, glycaemic load and subsequent changes of weight and waist circumference in European men and women. Int J Obes (Lond) 33, 1280-1288.

76. Kay SJ \& Fiatarone Singh MA (2006) The influence of physical activity on abdominal fat: a systematic review of the literature. Obes Rev 7, 183-200.

77. Macdiarmid J \& Blundell J (1998) Assessing dietary intake: who, what and why of under-reporting. Nutr Res Rev 11, 231-253.

78. Lafay L, Basdevant A, Charles MA et al. (1997) Determinants and nature of dietary underreporting in a free-living population: the Fleurbaix Laventie Ville Sante (FLVS) Study. Int J Obes Relat Metab Disord 21, 567-573.

79. Lafay L, Mennen L, Basdevant A et al. (2000) Does energy intake underreporting involve all kinds of food or only specific food items? Results from the Fleurbaix Laventie Ville Sante (FLVS) study. Int J Obes Relat Metab Disord 24, 1500-1566. 